\title{
Optimising the mutation screening strategy in Marfan syndrome and identifying genotypes with more severe aortic involvement
}

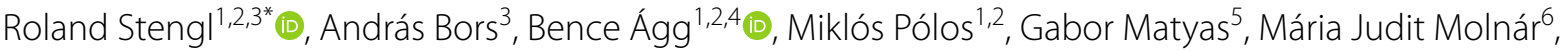 \\ Bálint Fekete ${ }^{6}$, Dóra Csabán ${ }^{6}$, Hajnalka Andrikovics ${ }^{3}$, Béla Merkely' ${ }^{1}$, Tamás Radovits' ${ }^{1}$ Zoltán Szabolcs ${ }^{1,2 \dagger}$ \\ and Kálmán Benke $e^{1,2+}$
}

\begin{abstract}
Background: Marfan syndrome (MFS) is a systemic connective tissue disorder with life-threatening manifestations affecting the ascending aorta. MFS is caused by dominant negative (DN) and haploinsufficient (HI) mutations of the FBN1 gene. Our aim was to identify mutations of MFS patients with high detection rate and to investigate the use of a gene panel for patients with Marfanoid habitus. We also aimed to examine correlations between genotype and cardiovascular manifestations to predict "malignant" mutations.

Methods: 136 individuals were enrolled. In the first phase, next-generation sequencing (NGS) and Sanger sequencing were performed for 57 patients to screen the FBN1 gene, followed by multiplex ligation-dependent probe amplification (MLPA) in negative cases. For repeated negative results, NGS gene panel involving 9 genes was used. In the second phase, 79 patients were tested primarily with the same gene panel, negative samples were tested by MLPA.

Results: 84 pathogenic mutations were detected, out of which 78 affected FBN1, 6 non-FBN1 mutations (2 TGFB2, 1 TGFBR2, 2 TGFBR1, 1 SMAD3) are associated with Loeys-Dietz syndrome (LDS). LDS patients had lower systemic score and they were younger, but their aortic involvement did not differ. MLPA detected 4 multi-exon deletions of FBN1 gene, which could not be identified by our first-step screening method. Aortic involvement (aortic dissection and/or dilation) did not differ significantly among $\mathrm{HI}$ and DN mutations ( $p=0.061)$. Combined group of $\mathrm{HI}$ and DN mutations eliminating a disulphide-bonding cysteine (DN Cys) had significantly higher aortic involvement rate than DN mutations not eliminating a disulphide-bonding cysteine (DN non-Cys) $(p<0.001)$. Patients with DN Cys required significantly more aortic surgeries than $\mathrm{HI}$ and DN non-Cys mutations ( $p=0.042$ and $p=0.015$, respectively).

Conclusions: Due to the relevant number of mutations affecting genes other than $F B N 1$, preferred approach for testing individuals with Marfanoid habitus is using a gene panel rather than single-gene analysis, followed by MLPA for negative samples. DN Cys and HI mutations should be considered as risk factors for aortic involvement. Genetic testing for patients with Marfanoid features and a systemic score under 7 is recommended, as LDS patients may have lower scores, but they may have severe cardiovascular manifestations.
\end{abstract}

\footnotetext{
*Correspondence: rolandstengl01@gmail.com

†Zoltán Szabolcs and Kálmán Benke contributed equally to this work.

1 Heart and Vascular Center, Semmelweis University, Városmajor u. 68, Budapest 1122, Hungary

Full list of author information is available at the end of the article
} permits use, sharing, adaptation, distribution and reproduction in any medium or format, as long as you give appropriate credit to the original author(s) and the source, provide a link to the Creative Commons licence, and indicate if changes were made. The images or other third party material in this article are included in the article's Creative Commons licence, unless indicated otherwise in a credit line to the material. If material is not included in the article's Creative Commons licence and your intended use is not permitted by statutory regulation or exceeds the permitted use, you will need to obtain permission directly from the copyright holder. To view a copy of this licence, visit http://creativecommons.org/licenses/by/4.0/. The Creative Commons Public Domain Dedication waiver (http://creativeco mmons.org/publicdomain/zero/1.0/) applies to the data made available in this article, unless otherwise stated in a credit line to the data. 
Keywords: Marfan syndrome, Genetic testing, Aortic involvement, Risk stratification, FBN1, Next-generation sequencing, MLPA, Gene panel, Cardiac surgery

\section{Background}

Marfan syndrome (MFS) is a systemic connective tissue disorder with a prevalence of 1:3000-1:5000 [1]. The main clinical manifestations typically involve the cardiovascular $(\mathrm{CV})$, musculoskeletal and ocular systems [2].

The disease is inherited in an autosomal dominant manner and caused by mutations of the FBN1 gene, which is located on the long arm of chromosome 15 (15q21.1) and consists of 65 coding exons [3]. It encodes the fibrillin-1 protein, which is secreted into the extracellular matrix and cooperates with elastin to build up the connective tissue through the formation of elastic fibres. It also has structural roles even independently from elastin, for example building up ciliary zonules in the eye [4]. Its regulatory function is to keep transforming growth factor- $\beta$ (TGF- $\beta$ ) in an inactive form [5]. A particularly important amino acid in the structure of fibrillin- 1 is cysteine, of which more than 360 can be found in the protein. Cysteine plays a critical role in the stability of fibrillin-1 due to the formation of disulphide bridges [6]. Mutations that eliminate this amino acid have been proved to result in more severe $\mathrm{CV}$ involvement than the ones introducing new cysteine $[7,8]$, emphasising the particular role of this disulphide-bonding amino acid.

To date, more than 3000 genetic variants of the FBN1 gene have been reported in the Human Gene Mutation Database [9]. They spread throughout the gene, affecting all exons [3]. Around half of them are missense mutations, the others are nonsense, splice-site mutations, and small in-frame or, frameshift insertions and deletions (indels, $\leq 50 \mathrm{bp}$ ) or copy number variations (CNVs, $>50$ bp) $[9,10]$. CNVs are deletions and duplications affecting more than $50 \mathrm{bp}$ and they account for around $10 \%$ of disease-causing genetic variants in Mendelian diseases [11]. FBN1 mutations can be classified into haploinsufficient (HI) and dominant negative (DN) groups based on their effect on the encoded protein. HI mutations result in the reduction of protein quantity, therefore in this case, only/mainly the normal protein can be found in the connective tissue [12, 13]. As opposed to that, DN mutations lead to abnormal protein structure, so the connective tissue contains both the normal and abnormal fibrillin-1 [14].

Genetic testing of the FBN1 gene has been receiving growing attention in the past few years and besides clinical features, it has become one of the key criteria of the diagnosis of MFS in the revised Ghent nosology [2].
To date, only a few well-established connections between genetic background and phenotype have been described [15], e.g. FBN1 mutations affecting a cysteine amino acid are more likely to lead to ectopia lentis [16]. There is also a strong relationship between the severity of MFS and a specific part of the gene: if the so-called neonatal region, which is spread throughout the exons 24-32, is affected, then there is a significantly increased chance for the occurrence of neonatal MFS, which is the most severe form of the disease [16]. Mutations in this region were found to lead to a higher probability of ascending aortic dilation, aortic surgery, mitral valve abnormalities, ectopia lentis, scoliosis and shorter survival even when neonatal MFS was excluded. Therefore, a genetic variant in the region of exons 24-32 can result in a more severe phenotype and can be an indicator of early onset aortic risk even in the absence of neonatal MFS [16].

Establishing the differential diagnosis is an important aspect as many related disorders of MFS lead to similar clinical appearance, but require different therapeutic approach [2]. Comparing to MFS, the Marfan-related Loeys-Dietz syndrome (LDS) may present with more aggressive clinical presentation, characterised by rapidly growing aneurysms, and aortic dissections occurring at a younger age and with smaller diameters. Furthermore, LDS dissections can take place in the peripheral arteries too. These indicate the need for more frequent and extended surveillance and lower aortic diameter as the indication criterion for a prophylactic surgery [17]. Therefore, differentiating between MFS and LDS carries huge clinical importance. In LDS, the TGFBR1, TGFBR2, SMAD3, TGFB2, TGFB3 and SMAD2 genes are affected [18]. On the other hand, some of the diseases that result in a Marfan-like appearance may not lead to severe CV complications. One example of that is congenital contractural arachnodactyly (Beals syndrome), which is caused by a mutation in the FBN2 gene [19]. Therefore, it is pivotal to identify the actual syndrome the patient has, so the proper management can be carried out.

Some of the characteristic features of MFS are aortic dilation and dissection, mitral valve prolapse, chest deformities, dolichostenomelia, scoliosis, skin striae, myopia and ectopia lentis [2].

The most dangerous, life-threatening complication of MFS and other genetic aortopathies is aortic dissection, which occurs at the average age of 63 years in the general population, $\sim 38$ years in MFS [20] and $\sim 27$ years in 
LDS patients [21]. Approximately two-thirds of aortic dissections belong to group type A in the Stanford classification system, meaning that they involve the ascending aorta. Without surgical intervention, an acute type A aortic dissection has a mortality rate of $20 \%$ after $24 \mathrm{~h}$ and it increases to $30 \%$ after $48 \mathrm{~h}$ [22]. The mortality of the operation of an acute type A aortic dissection can reach even $20 \%$, while it is only around $1.5 \%$ in case of prophylactic surgery [23].

The indication for prophylactic surgery is based on aortic diameter. The threshold is $50 \mathrm{~mm}$ for MFS patients, which goes down to $45 \mathrm{~mm}$ in the presence of any of the risk factors stated in the European Society of Cardiology (ESC) guidelines [24]. The main concern is that a relevant number of aortic dissections occur at smaller diameters. In a study by Neri and his colleagues, one-third of aortic dissections took place at normal or mildly enlarged diameters [25], and in another article, Kim and his colleagues reported a smaller than $45 \mathrm{~mm}$ aortic diameter for $26 \%$ of dissections [26]. However, too early, and unnecessary operations should be also avoided. As aortic diameter alone is not appropriate to predict aortic dissection, a model that could precisely determine the risk and the possible onset should be created [27-29].

Therefore, our research aimed to identify the pathogenic genetic variants of clinically diagnosed MFS patients with the highest achievable detection rate. We also aimed to examine the relevance of the use of a multigene panel in the investigation of patients with a Marfanoid habitus.

Our further objective was to identify genotype-phenotype correlations that could improve the risk stratification for severe aortic events and could be applied within clinical settings.

\section{Patients and methods}

\section{Studied population}

At the Heart and Vascular Center of Semmelweis University in Budapest, Hungary, the Marfan out-patient clinic was established to follow-up and treat patients and also help to orientate people with the clinical suspicion of the disease. MFS patients are registered in the Hungarian Marfan Register, maintained by the Hungarian Marfan Foundation. The database includes more than 500 patients [30].

Until December 2019, 136 patients underwent genetic testing. After informed genetic counselling and written consent, blood sample was collected, and DNA was isolated (ETT TUKEB 12751-3/2017/EKU).

\section{Study design}

The study was divided into two distinct phases. In the first phase, 57 patients were involved. The second phase included patients with negative results from the first phase and further 79 newly enrolled patients. The participants enrolled at different periods are referred to as first $(n=57)$ and second $(n=79)$ set of patients. The inclusion criterion in the first phase was the clinical diagnosis of MFS; in the second phase, patients with the clinical diagnosis of MFS and patients with Marfanoid habitus were included. We defined Marfanoid habitus as having a systemic score of at least 5 points. The clinical diagnosis was based on the revised Ghent nosology [2].

The first phase took place in 2017 and 2018, while the second phase was carried out in 2019. The reasons for establishing two distinct phases were the questions emerging during the experiment, which required more advanced diagnostic tools. Patients were selected in the order of visiting the clinic.

We decided to include first-degree relatives who presented with Marfanoid features regardless of their systemic score, as the disease shows a high interpersonal phenotypic variability. The 136 patients, including 18 first-degree relatives, came from 118 families.

\section{Single-gene analysis}

Step 1: In the first phase, we screened for mutations of the FBN1 gene with the use of next-generation sequencing (NGS) technique as previously described [31]. We applied a Roche GS Junior platform.

Step 2: Homopolymer regions were investigated with Sanger sequencing with the use of ABI Prism 310 Genetic Analyser (Applied Biosystems) and all the detected (likely) pathogenic mutations were confirmed by this technique.

\section{Multi-gene panel analysis}

In the second phase of the study, we applied an NGS based multi-gene panel, which covered the potential genes of Marfan syndrome and its overlapping related disorders, to increase our detection rate and to enable a differential diagnosis to be established. These involved the following 9 genes: ACTA2, COL3A1, FBN1, KCNN1, MYH11, SMAD3, TGFB2, TGFBR1 and TGFBR2. The mutations of these genes can lead to heritable aortopathies, including MFS, LDS, vascular Ehlers-Danlos syndrome (vEDS) and familial thoracic aortic aneurysm and dissection (FTAAD) [32]. With the multi-gene panel method, we examined the samples of a total number of 96 patients. The genomic DNA libraries were prepared by using QIAseq targeted DNA custom panel (QIAGEN, USA); for the subsequent NGS, we applied the Illumina MiSeq platform (Illumina, San Diego, USA). The Variant Call Format (VCF) files were annotated with the SnpEff 
software [33] and the ClinVar database [34]. The variant classification was carried out by using the VariantAnalyzer software developed by the Budapest University of Technology and Economics. Various databases were used to interpret the pathogenicity of a rare variant. These included Varsome [35], Human Gene Mutation Database [9], Universal Mutation Database [36, 37], dbSNP [38], and gnomADv2.1 non-Finnish population. The variant classification was performed according to ACMG guidelines [39].

Pathogenic and likely pathogenic missense mutations were classified as DN variants, while nonsense, splice-site and frameshift mutations and CNVs were considered as HI genetic variants.

\section{MLPA}

When no pathogenic mutations were detected by sequencing, we applied the multiplex ligationdependent probe amplification (MLPA) technique to screen for CNVs of the FBN1 and TGFBR2 genes [31] (MRCHolland, Amsterdam, the Netherlands), as the sequencing methods used in this study are not or less capable to detect CNVs in heterozygous form. MLPA was performed in 19 and 30 patients in phase 1 and 2, respectively.

\section{Investigation of genotype-phenotype correlations}

When (likely) pathogenic genetic variants were identified, we examined the correlations between the severity of $\mathrm{CV}$ manifestations and the genotype. We focused on the involvement of the ascending aorta, including dilation and dissection. Dilation is defined by the Z-score reaching and exceeding 2 above 20 years, and 3 below 20 years [2]. The frequency of these CV complications were compared between (likely) pathogenic variant positive and negative patients and also between patients with $\mathrm{HI}$ and DN mutations of the FBN1 gene. Based on the crucial role of cysteine in protein structure, we further stratified DN mutations into genetic variants that resulted in the elimination of disulphide-bonding cysteine (DN Cys) and the ones that did not substitute such amino acid (DN non-Cys). We analysed the need for aortic surgeries among the different mutation types of the FBN1 gene. We also compared the aortic involvement of MFS/LDS patients to the group of no identified mutations. Finally, we investigated the well-known genotype-phenotype correlations in our patient cohort.

\section{Statistical analysis}

We used two-sample $t$-test and chi-squared test to compare certain groups; results were considered significant at $p<0.05$. To describe the general characteristics of the examined population, we calculated the mean and
95\% confidence interval; for the systemic score, we used median with first and third interquartile range.

\section{Results}

Figure 1 shows the distribution of genetic screening steps applied for the two sets of patients and the results of the two phases of the study.

\section{Results of phase I}

The examined population in the first phase of the genetic testing consisted of 19 men (33\%) and 38 women (67\%) with an average age of $33(30-37)$ years at the time of the genetic screening. Their median systemic score was 8 (ranging from 7 to 10 ).

Altogether 34 (likely) pathogenic mutations of the FBN1 gene were identified with the use of NGS and Sanger sequencing, resulting in a detection rate of $60 \%$ (34/57). These included 17 missense (50\%), 8 nonsense (23\%), 5 frameshift (15\%) and 4 splice-site (12\%) mutations. We identified 2 missense variants of unknown significance (VUS). In 19 of the 21 MFS cases with no identified FBN1 mutations, we applied MLPA to screen for CNVs and we had three positive results in the FBN1 gene $(16 \%)$. In one patient, it caused the deletion of exons 1-2 and for the other patients, exons 2-4 were deleted.

The average age of patients with identified mutations was $37(32-41)$ years with a median systemic score of 8 (ranging from 7 to 10 ).

The 20 MFS patients with no detected (likely) pathogenic FBN1 mutation had an average age of 27 (22-32) years and a median systemic score of 7.5 (ranging from 6 to 9). Therefore, in terms of the systemic score, there was no significant difference between people with or without identified mutations $(p=0.100)$, but people without identified mutations were significantly younger $(p=0.011)$.

\section{Results of phase II}

In the second phase of the research, 30 pathogenic variants were identified, 27 of which affected the FBN1 gene (90\%), including 3 missense (11\%), 7 nonsense (26\%), 7 frameshift (26\%) and 10 splice-site (37\%) mutations. One nonsense and 2 frameshift mutations affected TGFBR2 (3.3\%) and TGFB2 (6.7\%), respectively. Also, 16 likely pathogenic mutations were detected, 13 of which affected the $F B N 1$ gene $(81 \%)$, including 10 missense mutations (76.9\%), and 3 in-frame deletions (23.1\%). Two likely pathogenic missense variants affected the TGFBR1 gene (12.5\%). One likely pathogenic missense variant was identified in the SMAD3 gene. The average age of the group of people with pathogenic or likely pathogenic genetic variants was 36 (33-40) years and their median systemic score was 8 (ranging from 7 to 9 ). 


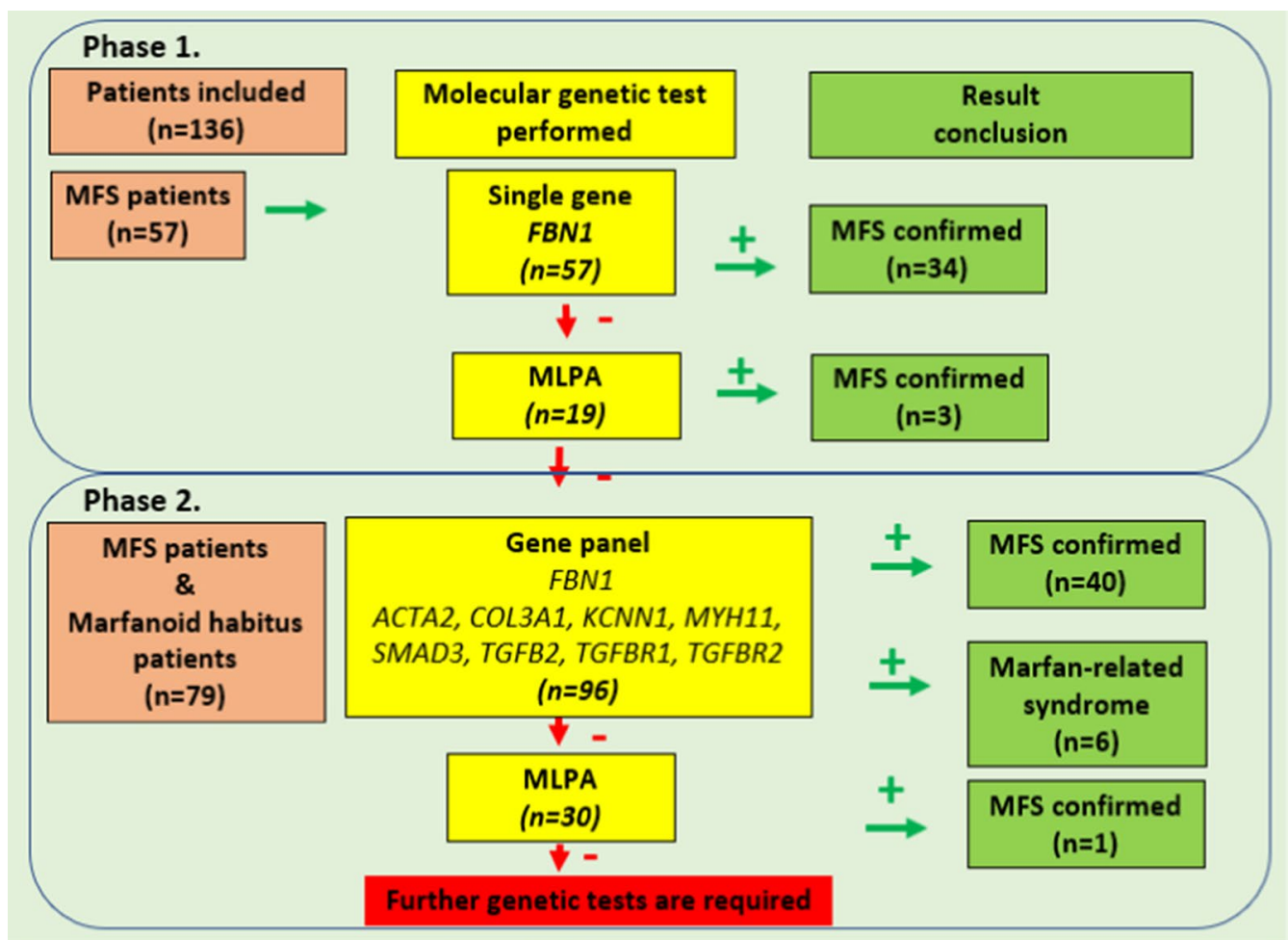

Fig. 1 Summary of the genetic testing steps. Genetic screening steps for two sets of patients. We started the genetic testing with sequencing the FBN1 gene. The negative samples were further investigated with MLPA technique. We applied an NGS gene panel for the samples with repeated negative results. We applied the gene panel followed by MLPA for the second set of patients. The two phases of the study are indicated

In 8 samples, we detected variants of unknown significance (VUS). One missense and 2 non-coding VUS affected the $F B N 1$ gene (37.5\%) and 2 missense VUS were found in MYH11 (25\%), 2 VUS in ACTA2 (25\%), and 1 VUS in the KCNN1 (12.5\%) gene. Four of them were detected in people with an identified (likely) pathogenic variant, and the other 4 appeared to be the only detected mutation. The latter 4 genetic variants need to undergo further investigations. The distribution of the mutations identified by the gene panel can be seen in Fig. 2 .

From the second set of patients, 30 variant negative samples were further analysed using MLPA (Fig. 1). One $\mathrm{CNV}$ was identified, which involved the deletion of the exons 3-4 of the FBN1 gene.

\section{Overall results}

In the first set of patients, the detection rate of the FBN1 genetic variants appeared to be $65 \%$ (37/57), while in the second set of patients the FBN1 mutation identification rate was $52 \%(41 / 79)(p=0.13)$. Overall detection rate of the FBN1 mutations was $57 \%$ (78/136).

Altogether 84 positive mutations of the 136 examined patients were identified, which is a $62 \%$ overall success rate in mutation detection. Results were considered positive in the case of pathogenic and likely pathogenic variants, VUS and the rest accounted for the negative results [32]. The general characteristics and detailed Ghent nosology features of the patients with and without a positive mutation can be seen in Tables 1 and 2. Apart from their Body Mass Index, the general characteristics of the two population did not differ. The identified pathogenic and likely pathogenic genetic variants can be found in the additional file (see Additional file 1).

Out of the positive variants, 6 affected genes other than FBN1 (7\%); these 6 patients received the diagnosis of LDS. The general characteristics of MFS and LDS patients are shown in Table 3. The mutations affecting the $F B N 1$ gene led to a significantly higher systemic score than the ones found in other genes $(p=0.013)$. However, there was a tendency in the non- $F B N 1$ group to be younger $(p=0.057)$. Despite this, all the patients with a non-FBN1 mutation had a dilated ascending aorta, and 2 of them had already undergone prophylactic aortic root surgeries.

\section{Genotype-phenotype correlations}

We investigated the correlations between the genetic background and the clinical manifestations of our 


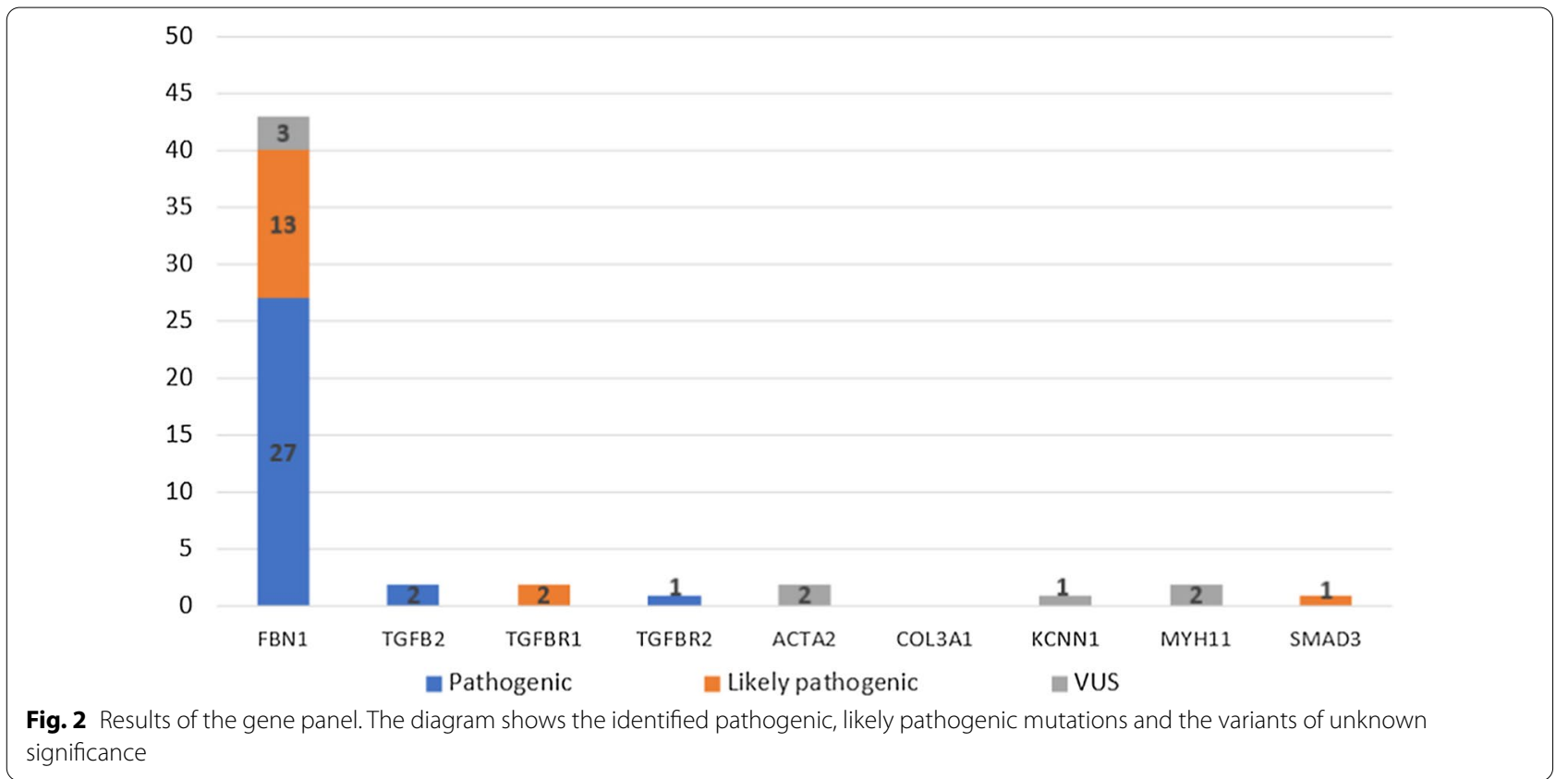

Table 1 General characteristics I

\begin{tabular}{|c|c|c|c|c|}
\hline & Studied population $(n=136)$ & Positive for mutation $(n=84)$ & $\begin{array}{l}\text { Not positive } \\
\text { for mutation } \\
(n=52)\end{array}$ & $\begin{array}{l}p \text { value (positive } \\
\text { vs. not positive) }\end{array}$ \\
\hline Male (\%) & 46 & 42 & 54 & 0.166 \\
\hline Age & $35(33-38)$ & $37(34-40)$ & $33(28-37)$ & 0.113 \\
\hline \multicolumn{5}{|l|}{ Anthropometric (measured) } \\
\hline Height $(\mathrm{cm})$ & $183.7(181.8-185.7$ & $183.4(180.9-185.8)$ & $184.4(181.2-187.6)$ & 0.604 \\
\hline Lower segment (cm) & $96.1(94.6-97.5)$ & $96.3(94.4-98.1)$ & $95.8(93.3-98.3)$ & 0.748 \\
\hline Arm span (cm) & $188.1(186.0-190.3)$ & $188.4(185.6-191.1)$ & $187.8(184.2-191.3)$ & 0.786 \\
\hline Footsize & $42.8(42.3-43.4)$ & $42.8(42.2-43.5)$ & $42.9(42.0-43.8)$ & 0.956 \\
\hline Weight (kg) & $70.3(67.3-73.3)$ & $72.0(68.3-75.7)$ & $67.5(62.3-72.7)$ & 0.153 \\
\hline \multicolumn{5}{|l|}{ Anthropometric (calculated) } \\
\hline Body Mass Index (BMl; kg/m²) & $20.7(20.0-21.4)$ & $21.3(20.4-22.1)$ & $19.7(18.5-21.0)$ & 0.042 \\
\hline Body surface area $\left(\mathrm{m}^{2}\right)$ & $1.88(1.84-1.93)$ & $1.91(1.85-1.96)$ & $1.85(1.77-1.93)$ & 0.230 \\
\hline $\begin{array}{l}\text { Upper segment-lower segment } \\
\text { ratio (USLS) }\end{array}$ & $0.92(0.90-0.94)$ & $0.91(0.88-0.93)$ & $0.93(0.90-0.97)$ & 0.218 \\
\hline Arm span-height ratio (ASHR) & $1.024(1.018-1.030)$ & $1.027(1.019-1.036)$ & $1.018(1.008-1.028)$ & 0.158 \\
\hline Systemic score & $8(7-9)$ & $8(7-9)$ & $8(7-9)$ & 0.249 \\
\hline
\end{tabular}

The table shows the general characteristics of the examined cohort with and without identified (likely) pathogenic genetic variants

The italics emphasises that the result is significant

patients. First, we examined the aortic involvement (dissection and/or dilation) among the $\mathrm{DN}$ and $\mathrm{HI}$ groups of the $F B N 1$ gene: $73 \%$ (22/30) of individuals with $\mathrm{DN}$ and $90 \%(43 / 48)$ of individuals with a HI genetic variant showed aortic involvement $(p=0.061)$. Then we investigated DN Cys and DN non-Cys variants, 89\% (16/18) of DN Cys mutations led to aortic dilation and/or dissection, while aortic involvement was only $50 \%(6 / 12)$ in case of DN non-Cys variants $(p=0.018)$. To make a classification which could be useful within clinical settings, we placed the DN Cys and HI mutations into one group and compared it to the DN non-Cys mutations. According to our results, DN non-Cys led to aortic involvement significantly less frequently than the combined group $(p<0.001)$ (Fig. 3a). DN Cys genetic variants required aortic surgeries significantly more frequently than HI 
Table 2 Ghent nosology

Examined population $(n=136)$ Mutation identified $(n=84) \quad$ No mutation identified

$(n=52)$

\begin{tabular}{|c|c|c|c|}
\hline \multicolumn{4}{|l|}{ Ghent nosology (\%) } \\
\hline \multicolumn{4}{|l|}{ Mitral valve prolapse } \\
\hline \multicolumn{4}{|l|}{ Dilation or dissection of descending aorta } \\
\hline \multicolumn{4}{|l|}{$\begin{array}{l}\text { Pectus carinatum } \\
\text { Petion or alssecton of descenaing aorta }\end{array}$} \\
\hline \multicolumn{4}{|l|}{ Pectus excavatum requiring surgery } \\
\hline \multirow{2}{*}{\multicolumn{4}{|c|}{$\begin{array}{l}\text { Reduced upper to lower segment ratio } \\
\text { Increased arm span to height ratio }\end{array}$}} \\
\hline & 23 & 27 & 15 \\
\hline \multicolumn{4}{|l|}{ Wrist sign } \\
\hline \multicolumn{4}{|l|}{ Thumb sign } \\
\hline \multicolumn{4}{|l|}{ Scoliosis of $>20^{\circ}$ or spondylolisthesis } \\
\hline \multicolumn{4}{|l|}{ Severe scoliosis } \\
\hline \multicolumn{4}{|l|}{$\begin{array}{l}\text { Reduced extension at the elbows } \\
\text { Medial displacement of the medial malleolus causing pes }\end{array}$} \\
\hline $\begin{array}{l}\text { Medial displacement of the medial malleolus causing pes } \\
\text { planus }\end{array}$ & 46 & 51 & 37 \\
\hline Heel deformity & 20 & 19 & 21 \\
\hline \multicolumn{4}{|l|}{ Protrusion acetabulae } \\
\hline \multicolumn{4}{|l|}{ Pectus excavatum of moderate severity } \\
\hline Asymetric chest & 46 & 50 & 40 \\
\hline \multicolumn{4}{|l|}{ Joint hypermobility } \\
\hline \multicolumn{4}{|l|}{ Highly arched palate with crowding of teeth } \\
\hline \multicolumn{4}{|l|}{ Dolichocephaly } \\
\hline \multicolumn{4}{|l|}{ Enophtalmos } \\
\hline \multicolumn{4}{|l|}{ Downslanting palpebral fissure } \\
\hline Malar hypoplasia & 13 & 17 & 6 \\
\hline Retrognathia & 40 & 48 & 29 \\
\hline \multicolumn{4}{|l|}{ Ectopia lentis } \\
\hline \multicolumn{4}{|l|}{ Myopia over 3 diopter } \\
\hline \multicolumn{4}{|l|}{ Abnormally flat cornea } \\
\hline Increased axial length of globe & 2 & 4 & 0 \\
\hline Hypoplastic iris & 1.5 & 2 & 0 \\
\hline \multicolumn{4}{|l|}{ Spontaneous pneumothorax } \\
\hline \multicolumn{4}{|l|}{ Apical blebs, bullae } \\
\hline \multirow{2}{*}{$\begin{array}{l}\text { Lumbosacral dural ectasia } \\
\text { Striae atrophicae (stretch marks) }\end{array}$} & 3 & 2 & 4 \\
\hline & 65 & 65 & 65 \\
\hline
\end{tabular}

This table shows the Ghent nosology features of the examined cohort with and without an identified (likely) pathogenic sequence variant

ones $(78 \%$ vs $50 \% ; p=0.042)$ and the DN non-Cys mutations $(78 \%$ vs $33 \% ; p=0.015)$ (Fig. $3 \mathrm{~b})$. The mean age at the time of surgery was 36 (28-44) years for DN Cys-, 32 (15-48) years for DN non-Cys- and 35 (31-38) years for HI patients. No significant difference could be observed in the age at the time of surgery among the 3 mutation types (DN Cys vs DN non-Cys $p=0.605$; DN non-Cys vs HI $p=0.524 ;$ DN Cys vs HI $p=0.757$ ).

The mean age at the last follow-up did not differ among the 3 mutation types. It was $43(36-51)$ years in the DN Cys-, 34 (28-40) years in the DN non-Cys- and 38
(34-41) years in the HI group (DN Cys vs DN non-Cys $p=0.074$; DN Cys vs HI $p=0.151$; DN non-Cys vs $\mathrm{HI}$ $p=0.382$ ).

All the individuals with the diagnosis of LDS (6/6) had either aortic dissection or dilation; aortic involvement was $83 \%$ (65/78) for MFS patients with identified genetic background and 38\% (20/52) for individuals without a detected sequence variant. Therefore, people with identified mutations had aortic involvement significantly more frequently than the patients without a detected mutation $(p<0.001)$. No difference could be observed between the 
Table 3 General characteristics II

\begin{tabular}{llll}
\hline & MFS $(\mathbf{n}=\mathbf{7 8})$ & LDS $(\mathbf{n}=6)$ & $p$ value \\
\hline Male (\%) & 41 & 50 & 0.667 \\
Age & $37.5(34.4-40.6)$ & $26.7(19.8-33.5)$ & 0.057 \\
Anthropometric (measured) & & & \\
Height (cm) & $183.5(180.9-186.0)$ & $182.2(170.2-194.2)$ & 0.777 \\
Lower segment (cm) & $96.7(94.8-98.5)$ & $91.6(82.2-101.0)$ & 0.153 \\
Arm span (cm) & $189.0(186.1-191.8)$ & $181.5(168.2-194.8)$ & 0.138 \\
Foot size & $42.9(42.2-43.6)$ & $42.6(37.9-47.3)$ & 0.854 \\
Weight (kg) & $72.7(68.9-76.6)$ & $63.3(48.8-77.9)$ & 0.164 \\
Anthropometric (calculated) & & & $18.94(15.97-21.93)$ \\
Body Mass Index (BMl; kg/m²) & $21.49(20.59-22.39)$ & $1.78(1.53-2.03)$ & $1.01(0.84-1.18)$ \\
Body surface area (mt) & $1.92(1.86-1.98)$ & $0.997(0.980-1.012)$ & 0.106 \\
Upper segment-lower segment ratio (USLS) & $0.90(0.88-0.92)$ & $6.5(6-7)$ & 0.209 \\
Arm span-height ratio (ASHR) & $1.030(1.021-1.039)$ & & 0.025 \\
Systemic score & $8(7-9)$ & & 0.013 \\
\hline
\end{tabular}

General characteristics of MFS and LDS patients are shown

The italics emphasises that the result is significant

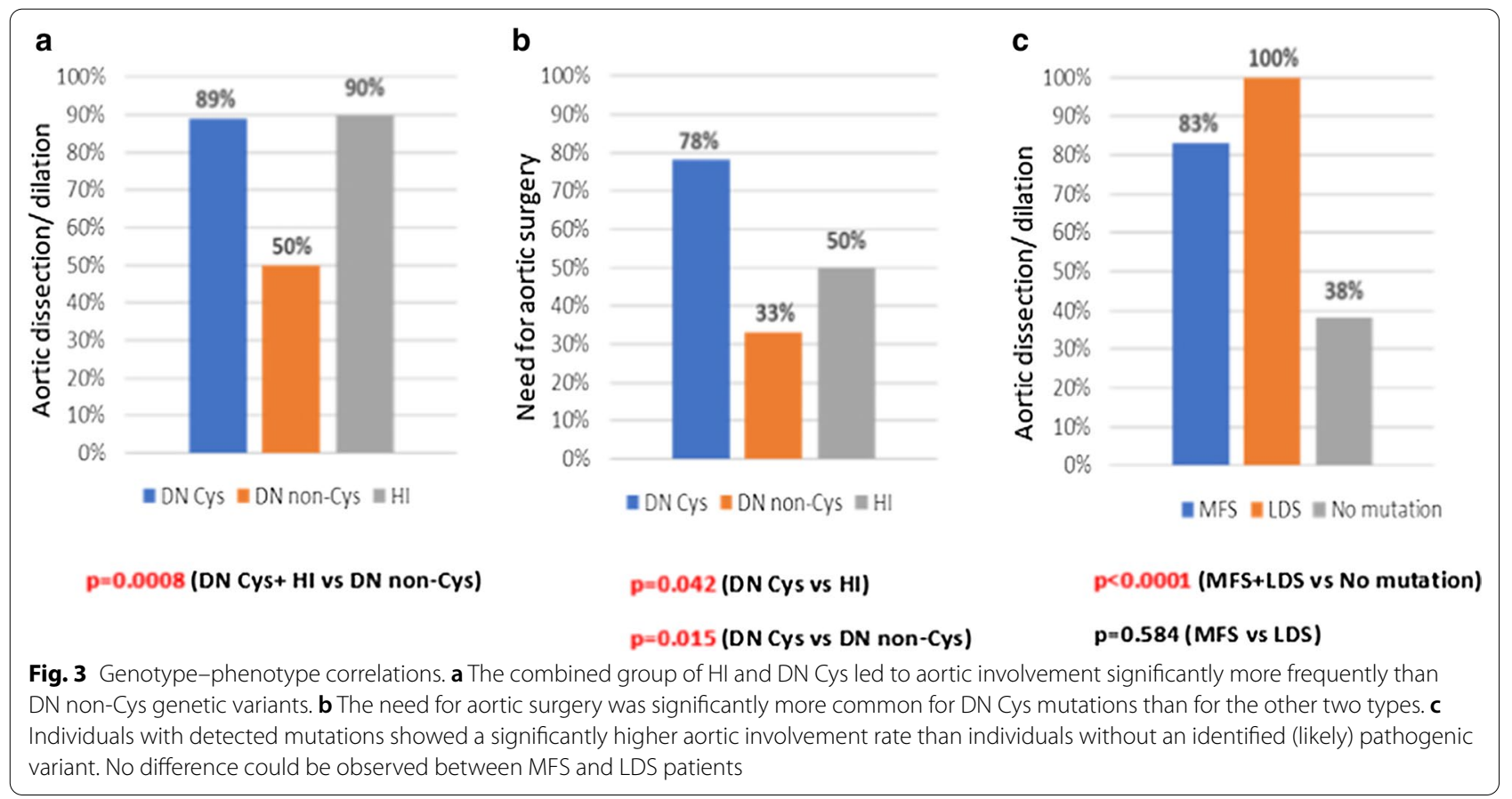

MFS and LDS groups $(p=0.584)$ (Fig. 3c). The general characteristics of MFS and LDS patients can be found in Table 3, showing that LDS patients have less severe anthropometric manifestations compared to MFS-cases.

Interestingly, 8 of the (likely) pathogenic $F B N 1$ variants occurred in the neonatal region (exons 24-32) and only one of them led to severe CV manifestation (prophylactic aortic surgery at the age of 17). The other cases presented as classical MFS. Of the 7 cases with a mutation in the neonatal region that presented as classical MFS, 6 developed aortic dilation without reaching the threshold for prophylactic surgery. There was no significant difference in terms of aortic involvement between patients with a mutation in exons $24-32(7 / 8)$ and patients with a mutation not affecting exons $24-32(58 / 70)(p=0.739)$.

In our patient cohort, $61 \%$ of DN Cys, $27 \%$ of $\mathrm{HI}$ and $14 \%$ of DN non-Cys mutations resulted in the dislocation of the lens. As a result, DN Cys led to ectopia lentis 
significantly more frequently than the HI, DN non-Cys and the combined group of $\mathrm{HI}$ and DN non-Cys mutations ( $p=0.011, p=0.008$ and $p=0.003$, respectively). This finding is consistent with the literature $[16,40]$.

\section{Discussion}

Currently, the most widely applied algorithm for genetic testing in MFS patients is the sequence analysis of the $F B N 1$ gene followed by $\mathrm{CNV}$ screening, and in negative cases the investigation of the TGFBR1 and TGFBR2 genes [41].

In our two-phase genetic testing study, we included 136 patients with either a clinical diagnosis of MFS or Marfanoid habitus, the first thorough genetic screening study of the Hungarian Marfan population. Due to the overlapping features of MFS and its related disorders, we used a multi-gene panel to investigate the relevant genes.

The mutation detection rate of $62 \%$ in our study is in the range found in the literature. The success of FBN1 mutation identification can be as high as $93 \%$ in individuals with clinically diagnosed MFS. However, this rate shows a huge variability. Arnaud and his colleagues had a 56\% detection rate in their study [42] while Baetens reached a $92 \%$ success rate [31]. The previously mentioned studies only investigated the $F B N 1$ gene, but examples of multigene testing are also available. Yang and his colleagues used a 15-gene aortopathy panel for 248 patients and they identified 92 (37.1\%) (likely) pathogenic mutations, $89 \%$ of them affecting the FBN1 gene [43]. In the study of Lerner-Ellis, 594 individuals with the suspicion of Marfan syndrome, Loeys-Dietz syndrome and Thoracic Aortic Aneurysms and Dissections were tested, and 112 individuals had a positive result (19\%). The authors state that the reason behind the low detection rate is the errors made during the patient selection process as they were not referred for testing by individuals with expertise in the field [44]. In a study by Wooderchak-Donahue, a 10-gene panel was applied, and 10.3\% of the 175 tested individuals appeared to be positive, while $18.3 \%$ had a VUS [41].

When we compared the general traits of patients with a detected mutation to the individuals without a detected mutation, only their Body Mass Index (BMI) differed significantly, the characteristic Marfanoid features and their systemic score were similar. This could suggest that errors in our patient selection were not the main reason for not reaching the maximal detection rate.

We investigated 9 genes, so one explanation for the lower success rate can be the involvement of other genes that were not covered by our gene panel. Mutations in the intronic regions have been reported [33], which could also contribute to our number, as we have not sequenced deep/non-canonical intronic regions.
We have identified $4 \mathrm{CNVs}$ of the FBN1 gene by MLPA, and they accounted for $\sim 5 \%$ of the detected mutations. Altogether 49 MLPA tests were carried out, so the detection rate was $\sim 8 \%$. Without this technique, these genetic variants would not have been detected, so the patients could not have received the benefits provided by an identified mutation.

Yang and his colleagues applied MLPA for 115 samples that came back negative after a 15-gene panel. As a result, they found 5 large deletions in the FBN1 gene (4.3\%) [45]. Consistently with our previous study, these findings highlight the importance of CNV screening in point-mutation negative cases, to increase the detection rate of diseasecausing genetic variants [11].

Increasing the mutation detection rate is highly important as identifying the patients' pathogenic mutation carries several benefits.

First, having an identified mutation helps to confirm the diagnosis of the disease. Therefore, it verifies the need for the management and treatment of the affected individuals. Furthermore, having a definite diagnosis makes it easier for patients to accept the fact that they must live with such a serious condition.

A detected pathogenic mutation can help to identify affected family members with targeted screening for the known genetic variant. This method is quick and inexpensive. When the result is negative, the disease can be excluded and unnecessary follow-ups can be avoided, no further management is required. Ruling out the possibility of the disease has a great influence on people's anxiety level and therefore the quality of life, as a significant difference was reported on the scores of trait anxiety between the Marfan and the normal population [46]. In the case of a positive test, adequate treatment and patient management need to be initiated. It is most useful in younger patients, as in most families phenotype only becomes apparent with increasing age [1], which makes the early diagnosis uncertain and delays the definite one. The clinical importance of early clinical diagnosis is the possibility of having a greater effect of early treatment to prevent the serious complications of the disease.

Patients can also benefit from knowing their diseasecausing mutation in the process of family planning. The parents could make their decision of having children with the information on their risk of passing on the disease to their offspring. A heterozygous MFS patient and a healthy individual have a $50 \%$ chance of passing on the mutation to their child.

A dynamically evolving field, where the identified mutation could be useful is preimplantation genetic diagnostics [47].

Seven percent of the identified (likely) pathogenic variants affected some of the genes associated with LDS, 
which is a related disorder of MFS with a potentially more aggressive clinical presentation. Therefore, it requires a different therapeutic approach, including follow-up with extended imaging and a lower aortic diameter threshold for prophylactic aortic root replacement surgery [17]. Our patients with LDS had a significantly lower systemic score and they showed a tendency to be younger than people with MFS. However, they both resulted in severe CV manifestations. In Hungary, our research group was the first that carried out genetic testing for LDS patients. The significance of making the right diagnosis can be clearly seen, and due to the overlapping clinical features, in certain cases, it can be achieved by using gene-panel testing.

Furthermore, 63\% (5/8) of VUS were found in genes other than FBN1.

Our finding that the mutations affecting the $F B N 1$ gene led to a significantly higher systemic score than the ones found in other genes, could indicate the need for gene panel testing even in patients with Marfan-like characteristics whose systemic score does not reach the threshold of 7 points.

The considerable number of non-FBN1 mutations identified suggests that gene panel testing should be preferred instead of single gene screening in patients with the suspicion of Marfan syndrome and related disorders.

The clinically most relevant use of genotype-phenotype correlations is identifying genetic variants which are associated with more severe CV involvement.

We found that the combined group of HI and DN Cys mutations led to aortic involvement (aortic dissection, aortic dilation) significantly more frequently than DN non-Cys genetic variants. Furthermore, aortic surgery was significantly more common among patients with DN Cys mutations than in the other two groups. Our results show a strong correlation between the type of mutation and the severity of $\mathrm{CV}$ manifestations, which has the potential to improve the risk stratification of the patients in order to optimise the decision making on the necessity and timing of prophylactic aortic root surgeries.

Some articles focusing on the connections between the genotype and $\mathrm{CV}$ involvement have been published. Becerra-Muñoz and his colleagues carried out genetic testing for 108 individuals with suspected MFS and they detected 90 FBN1 mutations. They found that patients with MFS and truncating variants had a higher percentage of aortic events than patients with a missense mutation [15]. Similarly, after examining 179 probands with pathogenic or likely pathogenic mutations, Baudhuin and colleagues reported a higher frequency of truncating and splicing variants in patients with an aortic event. They also found that patients with these mutations had an aortic event at a younger age than people with a missense variant [48]. The results of Franken et al. also support these findings by stating that $\mathrm{HI}$ patients have a 2.5-fold higher risk of CV death, a 2.4-fold increased risk of reaching the combined endpoint of dissection or death and a 1.6-fold higher risk of any aortic complication compared to DN mutations [49]. These articles treat the missense mutations as a homogenous group, and they all consider this mutation type as lower risk for serious $\mathrm{CV}$ manifestations. However, we further differentiated the DN group and we identified a subgroup that seems to be even more dangerous than the HI genetic variants.

Our findings support the results published by Takeda et al. on this topic. They also identified a subgroup within the DN mutations with a higher CV risk. As they reported, DN variants affecting or creating cysteine residues and in-frame deletions in exons $25-36$ and 43-49 (DN-CD) had a 6.3-fold higher risk for aortic events than the other DN mutations (DN-non CD), which is comparable with or more deleterious than $\mathrm{HI}$ variants. The growth of the aortic diameter also appeared to be larger in the $\mathrm{DN}-\mathrm{CD}+\mathrm{HI}$ group than in the $\mathrm{DN}$-non $\mathrm{CD}$ one [40]. Faivre et al. reported a significantly higher probability of ascending aortic dilation in patients with a mutation eliminating a cysteine than in patients with a variant resulting in cysteine creation [16]. These results also confirm the relevance of differentiating among DN mutations; however, we propose that DN Cys genetic variants could be considered higher CV risk than HI ones as they reached the need for aortic surgery significantly more frequently. There was no difference in their age at the last follow-up. More investigations need to be carried out to support this idea. Until then DN Cys and HI variants should be treated equally as high risk in the clinical practice. The location of the mutation can also have an impact on aortic involvement. In the above mentioned study by Faivre et al., mutations in exons 24-32 led to ascending aortic dilation significantly more frequently than variants found in other exons [16]. In contrast, our results did not show significant difference in terms of aortic involvement in patients with variants in exons 24-32 compared to individuals with mutations in other parts of the gene. However, the effect of the location of mutations is worth further investigating in future studies. The relevance of these studies is also highlighted by the finding that some patients with a DN non-Cys variant underwent aortic surgery at younger age than patients with DN Cys and HI mutations, even if no statistical difference could be observed in terms of age at the time of surgery among the mutation types. This could indicate that certain factors like location of mutation or affected domains may also influence CV severity. We are going to continue our study by involving further patients for gene panel testing. We also need to consider whether adding more genes to 
our panel would be a cost-effective way of increasing our detection rate.

\section{Limitations}

We acknowledge the limitations of our study, including the small sample size. However, it is comparable to the sample sizes of previous studies on this topic and we were able to draw significant conclusions on the studied cohort.

We analysed a limited number of genes, therefore our multi-gene panel did not cover all the known diseasecausing genes. In addition, the applied targeted screening method has its limitations, such as incomplete coverage and the need for regularly updating the gene panel due to novel gene-disease associations [10]. Despite these, our study successfully demonstrated the importance of using a multi-gene panel for patients with Marfanoid habitus.

Deep/non-canonical intronic regions were not sequenced, which could be a further limitation of our study [50].

Most of the patients in our study were started on antihypertensive drugs at the time of diagnosis of MFS or when significant and/or progressive aortic dilation was observed. Therefore, we cannot evaluate the contribution of the specific mutation and of the medication to the severity of aortic phenotype. However, as most MFS patients take blood pressure medications to prevent aortic complications, our study still provides relevant findings on the different effect of specific mutations on the severity of CV manifestations. It would be highly beneficial to carry out prospective studies to investigate the response of specific mutations to cardiac medications.

Prospective studies are needed to produce results that could be used in clinical practice in terms of genotype and CV manifestations. Despite the retrospective design of our study, it still provides significant findings on the correlations between genetic background and aortic involvement, and it could provide a base for further research.

\section{Conclusions}

Based on our results, we propose that the optimal way of genetic testing of MFS is the use of a gene panel, including FBN1 and MFS-related genes, combined with CNV analysis with MLPA, if necessary. A summary of the recommended algorithm can be found in Fig. 4. This method can help to make the exact diagnosis and increase the detection rate.

We emphasize the need for genetic testing for patients who show Marfanoid features but their systemic score is below 7, as LDS patients may have lower scores, but they are likely to have severe $\mathrm{CV}$ manifestations.

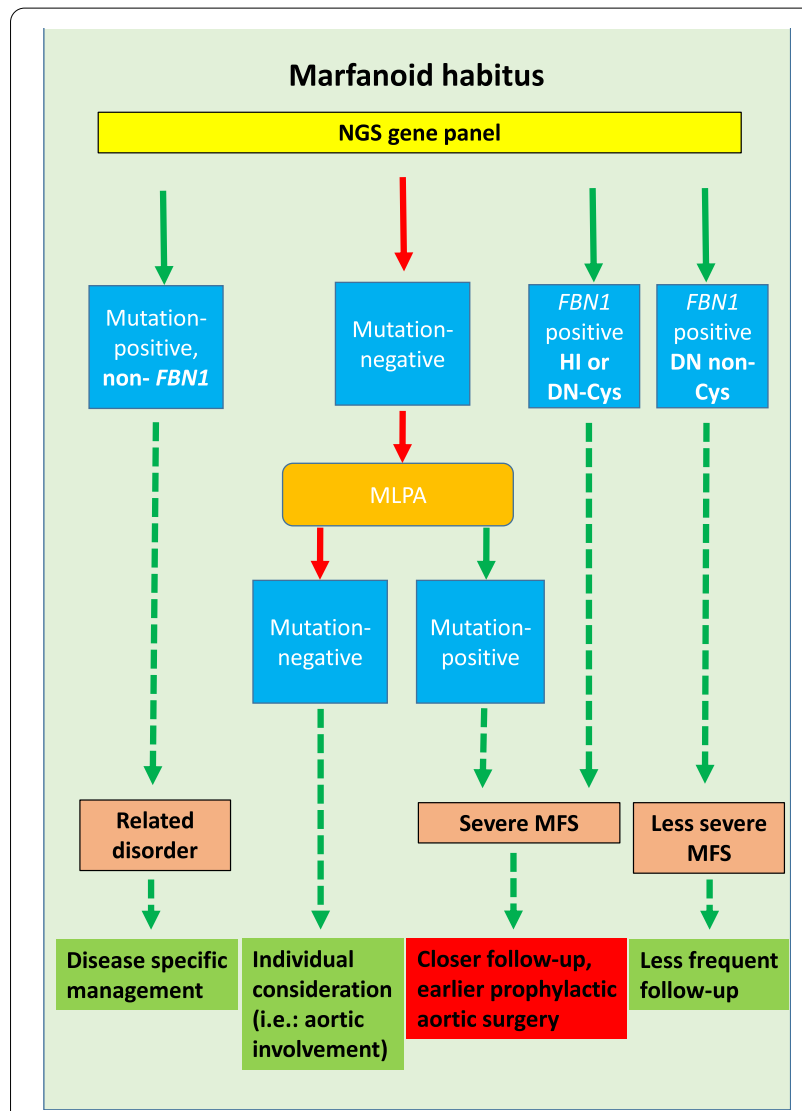

Fig. 4 Recommended screening algorithm. People with suspected Marfan syndrome should undergo genetic screening. We recommend the use of a gene panel, followed by MLPA in negative cases. When $\mathrm{HI}$ or DN Cys mutations are identified, closer follow-up and earlier prophylactic surgery should be considered. DN non-Cys sequence variants should be managed as stated in the current ESC guidelines. When a (likely) pathogenic variant is detected in a gene other than the FBN1, then appropriate management of the identified disease/syndrome needs to be carried out. The management of people without a detected mutation should be based on the clinical presentation, mostly focusing on aortic involvement

MFS patients with DN Cys and HI mutations are at increased risk for aortic involvement, and DN Cys mutations seem to lead to the most severe aortic involvement. This finding could have an impact on patient management; however, further research is required to enable genetic information to be included in the risk stratification.

\section{Supplementary information}

Supplementary information accompanies this paper at https://doi. org/10.1186/s13023-020-01569-4.

Additional file 1: Identified (likely) pathogenic mutations. 


\begin{abstract}
Abbreviations
ACTA2: Actin alpha 2, smooth muscle gene; CNV: Copy number variation: COL3A1: Collagen type III alpha 1 chain gene; CV: Cardiovascular; DN: Dominant negative; DN-CD: DN variant affecting or creating cysteine residues and in-frame deletion variants in the central cb-EGF domains (exons 25-36 and 43-49); DN-Cys: DN mutation eliminating a disulphide-bonding cysteine; DNnonCD: DN variant not affecting nor creating cysteine residues and in-frame deletion variants in the central cb-EGF domains (exons 25-36 and 43-49); DN non-Cys: DN mutations not eliminating a cysteine; ESC: European Society of Cardiology; FBN1: Fibrillin-1 gene; FBN2: Fibrillin-2 gene; FTAAD: Familial thoracic aortic aneurysm and dissection; $\mathrm{HI}$ : Haploinsufficient; KCNN1: Potassium calcium-activated channel subfamily N member 1 gene; LDS: Loeys-Dietz syndrome; MFS: Marfan syndrome; MLPA: Multiplex ligation-dependent probe amplification; MYH11: Myosin heavy chain 11 gene; NGS: Next-generation sequencing; SMAD3: SMAD family member 3 gene; TGF- $\beta$ : Transforming growth factor- $\beta$; TGFB2: Transforming growth factor beta 2 gene; TGFB3: Transforming growth factor beta 3 gene; TGFBR1:Transforming growth factor beta receptor 1 gene; TGFBR2: Transforming growth factor beta receptor 2 gene; vEDS: Vascular Ehlers-Danlos syndrome; VUS: Variants of unknown significance.
\end{abstract}

\section{Acknowledgements}

The authors would like to thank the community of the Hungarian Marfan syndrome patients. We also thank the members of the Hungarian Marfan Foundation for their support.

\section{Authors' contributions}

RS participated in the genetic testings, patient examinations, data collection, analysis and interpretation of data, performed the statistical analysis and drafted the manuscript. AB, HA, DCS carried out genetic testings, participated in the analysis and interpretation of data and drafted the manuscript. BÁ and MP participated in data collection, drafted the manuscript and revised the intellectual content. MJM and BF carried out genetic counselling and drafted the manuscript. GM, BM and TR revised the manuscript and helped with professional advice. ZS and KB participated in patient selection, coordinated the study and established the study design. All authors read and approved the final manuscript.

\section{Funding}

This study was supported by the National Research, Development and Innovation Office of Hungary (NKFIA; NVKP_16-1-2016-0017 National Heart Program), by the Higher Education Institutional Excellence Programme of the Ministry for Innovation and Technology in Hungary, within the framework of the Therapeutic Development thematic programme of the Semmelweis University and by the "New National Excellence Program of the Ministry for Innovation and Technology" (ÚNKP-17-3-I-SE-31, ÚNKP-18-3-I-SE-69 and ÚNKP-19-3-I-SE-54; BÁ). A. Bors. was supported by the Janos Bolyai Research Scholarship of the Hungarian Academy of Sciences (BO/00809/18/8).

\section{Availability of data and materials}

The datasets used and/or analysed during the current study are available from the corresponding author on reasonable request.

\section{Ethics approval and consent to participate}

This study was performed in compliance with the Declaration of Helsinki and was approved by the Hungarian Medical Research Council (ETT TUKEB 127513/2017/EKU). Informed written consent was obtained from the participants.

\section{Consent for publication}

Not applicable.

\section{Competing interests}

The authors declare that they have no competing interests.

\footnotetext{
Author details

${ }^{1}$ Heart and Vascular Center, Semmelweis University, Városmajor u. 68, Budapest 1122, Hungary. ${ }^{2}$ Hungarian Marfan Foundation, Városmajor u. 68, Budapest 1122, Hungary. ${ }^{3}$ Laboratory of Molecular Genetics, Central Hospital of Southern Pest, National Institute of Hematology and Infectious Diseases, Albert Flórián út 5-7, Budapest 1097, Hungary. ${ }^{4}$ Department of Pharmacology and Pharmacotherapy, Semmelweis University, Üllői út 26, Budapest 1085, Hungary. ${ }^{5}$ Center for Cardiovascular Genetics and Gene Diagnostics,
}

Foundation for People With Rare Diseases, Wagistrasse 25, 8952 Schlieren, Zurich, Switzerland. ${ }^{6}$ Institute of Genomic Medicine and Rare Disorders, Semmelweis University, Tömő u. 25-29, Budapest 1083, Hungary.

Received: 7 June 2020 Accepted: 5 October 2020

Published online: 15 October 2020

\section{References}

1. Judge DP, Dietz HC. Marfan's syndrome. Lancet (London, England). 2005;366(9501):1965-76.

2. Loeys BL, Dietz HC, Braverman AC, Callewaert BL, De Backer J, Devereux $\mathrm{RB}$, et al. The revised Ghent nosology for the Marfan syndrome. J Med Genet. 2010;47(7):476-85.

3. Collod-Béroud G, Le Bourdelles S, Ades L, Ala-Kokko L, Booms P, Boxer M, et al. Update of the UMD-FBN1 mutation database and creation of an FBN1 polymorphism database. Hum Mutat. 2003;22(3):199-208.

4. Robertson I, Jensen S, Handford P. TB domain proteins: evolutionary insights into the multifaceted roles of fibrillins and LTBPS. Biochem J. 2011;433(2):263-76.

5. Benke K, Ágg B, Szilveszter B, Tarr F, Nagy ZBB, Pólos M, et al. The role of transforming growth factor-beta in Marfan syndrome. Cardiol J. 2013:20(3):227-34.

6. Vollbrandt T, Tiedemann K, El-Hallous E, Lin G, Brinckmann J, John H, et al. Consequences of cysteine mutations in calcium-binding epidermal growth factor modules of fibrillin-1. J Biol Chem. 2004;279(31):32924-311.

7. Landis BJ, Veldtman GR, Ware SM. Genotype-phenotype correlations in Marfan syndrome. Heart. 2017;103(22):1750-2.

8. Franken R, Heesterbeek TJ, De Waard V, Zwinderman AH, Pals G, Mulder BJ, et al. Diagnosis and genetics of Marfan syndrome. Expert Opin Orphan Drugs. 2014;2(10):1049-62.

9. Stenson PD, Ball EV, Mort M, Phillips AD, Shiel JA, Thomas NST, et al. Human Gene Mutation Database $\left(\mathrm{HGMD}^{\circledR}\right)$ : 2003 update. Hum Mutat. 2003;21(6):577-81.

10. Caspar SM, Dubacher N, Kopps AM, Meienberg J, Henggeler C, Matyas G. Clinical sequencing: from raw data to diagnosis with lifetime value. Clin Genet. 2018;93(3):508-19.

11. Benke K, Ágg B, Meienberg J, Kopps AM, Fattorini N, Stengl R, et al. Hungarian Marfan family with large FBN1 deletion calls attention to copy number variation detection in the current NGS era. J Thorac Dis. 2018;10(4):2456-60.

12. Mátyás G, Alonso S, Patrignani A, Marti M, Arnold E, Magyar I, et al. Large genomic fibrillin-1 (FBN1) gene deletions provide evidence for true haploinsufficiency in Marfan syndrome. Hum Genet. 2007;122(1):23-322.

13. Meienberg J, Rohrbach M, Neuenschwander S, Spanaus K, Giunta C, Alonso S, et al. Hemizygous deletion of COL3A1, COL5A2, and MSTN causes a complex phenotype with aortic dissection: A lesson for and from true haploinsufficiency. Eur J Hum Genet. 2010;18(12):1315-21.

14. Franken R, Teixido-Tura G, Brion M, Forteza A, Rodriguez-Palomares J, Gutierrez L, et al. Relationship between fibrillin-1 genotype and severity of cardiovascular involvement in Marfan syndrome. Heart. 2017;103(22):1795-9.

15. Becerra-muñoz VM, Gómez-doblas JJ, Porras-martín C, Such-martínez M, Crespo-leiro MG, Barriales-villa R, et al. The importance of genotypephenotype correlation in the clinical management of Marfan syndrome. Orphanet J Rare Dis. 2018;13:1-9.

16. Faivre L, Collod-Beroud G, Loeys BL, Child A, Binquet C, Gautier E, et al. Effect of mutation type and location on clinical outcome in 1,013 probands with Marfan syndrome or related phenotypes and FBN1 mutations: an international study. Am J Hum Genet. 2007;81(3):454-66.

17. MacCarrick G, Black JH, Bowdin S, El-Hamamsy I, Frischmeyer-Guerrerio PA, Guerrerio AL, et al. Loeys-Dietz syndrome: a primer for diagnosis and management. Genet Med. 2014;16(8):576-87.

18. Loeys BL, Dietz HC. Loeys-Dietz Syndrome Summary. 2019; p. 1-32. https ://www.ncbi.nlm.nih.gov/books/NBK1133/. Accessed 16 May 2020.

19. Tunçbilek E, Alanay Y. Congenital contractural arachnodactyly (Beals syndrome). Orphanet J Rare Dis. 2006;1(1):2-4. 
20. de Beaufort HWL, Trimarchi S, Korach A, Di Eusanio M, Gilon D, Montgomery DG, et al. Aortic dissection in patients with Marfan syndrome based on the IRAD data. Ann Cardiothorac Surg. 2017;6(6):633-41.

21. Loeys BL, Schwarze U, Holm T, Callewaert BL, Thomas GH, Pannu H, et al. Aneurysm syndromes caused by mutations in the TGF- $\beta$ receptor. N Engl J Med. 2006;355(8):788-98.

22. Lemaire SA, Russell L. Epidemiology of thoracic aortic dissection. Nat Rev Cardiol. 2011;8(2):103-13. https://doi.org/10.1038/nrcardio.2010.187.

23. Ades L. Guidelines for the diagnosis and management of Marfan syndrome. Hear Lung Circ. 2007;16(1):28-30.

24. Baumgartner H, Falk V, Bax JJ, De Bonis M, Hamm C, Holm PJ, et al. 2017 ESC/EACTS Guidelines for the management of valvular heart disease. Eur Heart J. 2017:38:2739-86.

25. Neri E, Barabesi L, Buklas D, Vricella LA, Benvenuti A, Tucci E, et al. Limited role of aortic size in the genesis of acute type $A$ aortic dissection. Eur J Cardio-thoracic Surg. 2005;28(6):857-63.

26. Kim EK, Choi SH, Sung K, Kim WS, Choe YH, Oh JK, et al. Aortic diameter predicts acute type $\mathrm{A}$ aortic dissection in patients with Marfan syndrome but not in patients without Marfan syndrome. J Thorac Cardiovasc Surg. 2014;147(5):1505-10. https://doi.org/10.1016/j.jtcvs.2013.05.025.

27. Ágg B, Benke K, Szilveszter B, Pólos M, Daróczi L, Odler B, et al. Possible extracardiac predictors of aortic dissection in Marfan syndrome. BMC Cardiovasc Disord. 2014;14(1):47.

28. Benke K, Ágg B, Mátyás G, Szokolai V, Harsányi G, Szilveszter B, et al. Gene polymorphisms as risk factors for predicting the cardiovascular manifestations in Marfan syndrome: role of folic acid metabolism enzyme gene polymorphisms in Marfan syndrome. Thromb Haemost. 2015;114(4).

29. Ágg B, Szilveszter B, Daradics N, Benke K, Stengl R, Kolossváry M, et al. Increased visceral arterial tortuosity in Marfan syndrome. Orphanet J Rare Dis. 2020;15:1-10.

30. Ágota A, Ágg B, Benke K, Joó JG, Langmár Z, Marosi K, et al. Marfanszindróma biobankjának létrehozása. Orv Hetil. 2012;153(8):296-302.

31. Baetens M, Van Laer L, De Leeneer K, Hellemans J, De Schrijver J, Van De Voorde $\mathrm{H}$, et al. Applying massive parallel sequencing to molecular diagnosis of Marfan and Loeys-Dietz syndromes. Hum Mutat. 2011;32(9):1053-62.

32. Goyal A, Keramati AR, Czarny MJ, Resar JR, Mani A. The genetics of aortopathies in clinical cardiology. Clin Med Insights Cardiol. 2017;11:1-11.

33. Cingolani P, Platts A, Wang LL, Coon M, Nguyen T, Wang L, et al. A program for annotating and predicting the effects of single nucleotide polymorphisms, SnpEff: SNPs in the genome of Drosophila melanogaster strain w1118; iso-2; iso-3. Fly (Austin). 2012;6(2):80-92.

34. Landrum MJ, Lee JM, Benson M, Brown G, Chao C, Chitipiralla S, et al. ClinVar: public archive of interpretations of clinically relevant variants. Nucleic Acids Res. 2016;44(D1):D862-D868868.

35. Kopanos C, Tsiolkas V, Kouris A, Chapple CE, Albarca Aguilera M, Meyer R, et al. VarSome: the human genomic variant search engine. Bioinformatics. 2019;35(11):1978-80.

36. Groth KA, Von Kodolitsch Y, Kutsche K, Gaustadnes M, Thorsen K, Andersen $\mathrm{NH}$, et al. Evaluating the quality of Marfan genotypephenotype correlations in existing FBN1 databases. Genet Med. 2017;19(7):772-7.

37. Béroud C, Collod-Béroud G, Boileau C, Soussi T, Junien C. UMD (Universal Mutation Database): a generic software to build and analyze locusspecific databases. Hum Mutat. 2000;15(1):86-94.
38. Sherry ST, Ward M, Sirotkin K. dbSNP-database for single nucleotide polymorphisms and other classes of minor genetic variation. Genome Res. 1999;9:677-9.

39. Richards S, Aziz N, Bale S, Bick D, Das S, Gastier-Foster J, et al. Standards and guidelines for the interpretation of sequence variants: a joint consensus recommendation of the American College of Medical Genetics and Genomics and the Association for Molecular Pathology. Genet Med. 2015;17(5):405-24.

40. Takeda N, Inuzuka R, Maemura S, Morita H, Nawata K, Fujita D, et al. Impact of pathogenic FBN1 variant types on the progression of aortic disease in patients with Marfan syndrome. Circ Genom Precis Med. 2018;11(6)::002058.

41. Wooderchak-Donahue W, Vansant-Webb C, Tvrdik T, Plant P, Lewis T, Stocks J, et al. Clinical utility of a next generation sequencing panel assay for Marfan and Marfan-like syndromes featuring aortopathy. Am J Med Genet Part A. 2015;167(8):1747-57.

42. Arnaud P, Hanna N, Aubart M, Leheup B, Naudion S, Lacombe D, et al. Homozygous and compound heterozygous mutations in the FBN1 gene: unexpected findings in molecular diagnosis of Marfan syndrome To cite this version: HAL Id : hal-01670201 Homozygous and compound heterozygous mutations in the gene: heterozygous unexpect. J Med Genet. 2017:54:125-33.

43. Yang H, Luo M, Fu Y, Cao Y, Yin K, Li W, et al. Genetic testing of 248 Chinese aortopathy patients using a panel assay. Sci Rep. 2016;6(August):1-8.

44. Lerner-Ellis JP, Aldubayan SH, Hernandez AL, Kelly MA, Stuenkel AJ, Walsh $J$, et al. The spectrum of FBN1, TGF $\beta R 1$, TGF $\beta R 2$ and ACTA2 variants in 594 individuals with suspected marfan syndrome, loeys-dietz syndrome or thoracic aortic aneurysms and dissections (TAAD). Mol Genet Metab. 2014;112(2):171-6. https://doi.org/10.1016/j.ymgme.2014.03.011.

45. Yang H, Ma Y, Luo M, Zhao K, Zhang Y, Zhu G, et al. Identification of gross deletions in FBN1 gene by MLPA. Hum Genom. 2018:12(1):1-7.

46. Benke K, Ágg B, Pólos M, Sayour AA, Radovits T, Bartha E, et al. The effects of acute and elective cardiac surgery on the anxiety traits of patients with Marfan syndrome. BMC Psychiatr. 2017;17(1):1-7.

47. Fragouli E. Preimplantation genetic diagnosis: present and future. J Assist Reprod Genet. 2007;24(6):201-7.

48. Baudhuin LM, Kotzer KE, Lagerstedt SA. Increased frequency of FBN1 truncating and splicing variants in Marfan syndrome patients with aortic events. Genet Med. 2015;17(3):177-87.

49. Franken R, Groenink M, De Waard V, Feenstra HMA, Scholte AJ, Van Den Berg MP, et al. Genotype impacts survival in Marfan syndrome. Eur Heart J. 2016;37(43):3285-90

50. Gillis E, Kempers M, Salemink S, Timmermans J, Cheriex EC, Bekkers SCAM, et al. An FBN1 deep intronic mutation in a familial case of marfan syndrome: an explanation for genetically unsolved cases? Hum Mutat. 2014;35(5):571-4

\section{Publisher's Note}

Springer Nature remains neutral with regard to jurisdictional claims in published maps and institutional affiliations.

Ready to submit your research? Choose BMC and benefit from:

- fast, convenient online submission

- thorough peer review by experienced researchers in your field

- rapid publication on acceptance

- support for research data, including large and complex data types

- gold Open Access which fosters wider collaboration and increased citations

- maximum visibility for your research: over $100 \mathrm{M}$ website views per year

At BMC, research is always in progress.

Learn more biomedcentral.com/submissions 